\title{
A EXPOSIÇÃO COMO DISPOSITIVO NA ARTE CONTEMPORÂNEA: CONEXÕES ENTRE O TÉCNICO E O SIMBÓLICO
}

\author{
Ana Maria Albani de Carvalho ${ }^{\text {* }}$ \\ Universidade Federal do Rio Grande do Sul
}

RESUMO:

No contexto cultural contemporâneo, marcado tanto pela globalização, quanto pelos investimentos em ações de alcance micro-político, é necessário indagar sobre as conexões nem sempre visíveis que constituem a rede que forma o campo da arte contemporânea. Seguindo esta linha de pensamento, este artigo procura elaborar uma reflexão sobre o papel da exposição no campo artístico contemporâneo. Percebida como um fenômeno cultural que se manifesta como um instrumento de poder, a exposição é definida como "dispositivo", um conceito que permite ir além do dualismo entre o técnico e o simbólico, que muitas vezes norteia o debate sobre o tema.

\section{PALAVRAS-CHAVE:}

Exposição; Arte Contemporânea, Dispositivo; Poder simbólico.
The art exhibit as dispositif in contemporary art: connections between the technical and the symbolic

\begin{abstract}
:
In the contemporary cultural context, distinguished both by globalization and by investments in micropolitical actions, it becomes necessary to question the not always visible connections of the net that creates the contemporary art field. In this perspective, this article aims at discussing the role of the art exhibit in the contemporary art field. Viewed both as a cultural phenomenon and as an instrument of power, the art exhibit is defined as dispositif, a concept that allows us to go beyond the dualism between the technical and the symbolic, which often guides this debate.
\end{abstract}

\section{KEYWORDS:}

art exhibit, contemporary art, dispositif, symbolic power.

\footnotetext{
I * Doutora em Artes Visuais - História, teoria e crítica (UFRGS), com estágio na École des Hautes Études en Science Sociales (EHHSS, França). Professora adjunta no departamento de Artes Visuais do Instituto de Artes da Universidade Federal do Rio Grande do Sul, responsável pelas disciplinas de Laboratório de Museografia e de Seminários de História da Arte Moderna. Pesquisadora e orientadora de mestrado e doutorado no Programa de Pós-Graduação em Artes Visuais, ministrando a disciplina Curadoria e Projetos de Exposição. Desenvolve trabalhos em curadoria e expografia e tem artigos e ensaios publicados sobre o tema, com ênfase em arte contemporânea.
} 
A exposição desempenha um papel central no campo das artes visuais, configurando-se como uma espécie de moldura - a qual pode assumir diferentes formatos ou privilegiar determinados enquadramentos - que afeta de forma significativa o modo de visualizar e pensar a arte. A própria narrativa apresentada pela história da arte, via de regra, considerada como a forma hegemônica de discurso "sobre" a arte e tradicionalmente focada no estudo da obra, é devedora ou está intrinsecamente articulada ao que se apresenta através das exposições e das políticas que os museus e centros culturais adotam para a constituição e o manejo de seus acervos, especialmente no que concerne à produção modernista e contemporânea.

Por outro lado, no cenário artístico configurado durante a última década, muitos artistas e também alguns curadores e críticos têm posto em discussão o formato expositivo tradicional criticando sua posição hegemônica enquanto modalidade fundamental para apresentação da arte, propondo outros veículos de difusão e outros formatos para a relação obra/público, seja através de apresentações verbo-visuais, publicações do gênero livro-de-artista ou emprego de mídias locativas digitais, entre outros recursos possíveis.

Perceber a exposição como um fenômeno cultural que se manifesta como "poderoso e eficaz instrumento de poder cultural" (GUASCH, 2000, p. 6), de um ponto de vista crítico e analítico, conduz à necessidade de indagar sobre seus pressupostos, seus métodos, suas práticas e especificidades enquanto veículo e recurso expressivo de ordem narrativa e interpretativa. Diferentemente de outros campos, como no caso das ciências naturais ou mesmo da história, no sistema das artes visuais, a exposição não desempenha apenas uma função comunicativa ou de "mediação". O que se define como arte - no caso das visuais, especialmente - é resultado de uma relação de reciprocidade entre $o$ trabalho de arte, o lugar onde este trabalho se espacializa e o observador/interagente, em um tipo de inscrição espaço-temporal.A exposição - aqui considerada no sentido das diferentes configurações através das quais uma obra pode instalar-se no espaço e também como evento -, é de ordem constitutiva para o campo das artes visuais, tanto no que concerne à produção artística, quanto a teórico-crítica.

Se no âmbito das exposições científicas - isto é, nos museus de ciências e tecnologia, de história natural e outros do gênero - a exposição constitui uma linguagem visual baseada e construída com "objetos que foram previamente codificados pela investigação científica” (BLANCO, 1999, p. 70), especialmente no campo da arte contemporânea, a exposição pode constituir-se como o momento de inscrição de um objeto, procedimento ou prática na "instituição arte" 2. Como argumenta Poinsot (1999, p. 35, tradução nossa), "não podemos considerar a exposição como uma linguagem secundária que veicula um signo pré-existente":

A exposição não se esgota na descrição dos micro-eventos que englobam a aparição de uma obra e não se limita à suas coordenadas

2 Com isto não pretendo diminuir ou negar o componente ideológico ou a dimensão discursiva presente nas exposições científicas, muito pelo contrário. É importante ressaltar, inclusive, o papel central que a expografia, muitas vezes pela via cenográfica, desempenha para a curadoria, a espacialização e a recepção das exposições científicas. Porém, no caso das ciências exatas, naturais ou dos museus e exposições de tecnologia, história e mesmo de outros segmentos do campo cultural, a exposição desempenha mais efetivamente um papel de difusão, divulgação e comunicação de um conhecimento anteriormente legitimado em outras instâncias. Entendo que é neste papel de legitimação e institucionalização que reside a diferença entre a função desempenhada pela exposição no campo das ciências e no das artes. 
espaço-temporais. A exposição é uma situação de discurso complexo que possui suas próprias regras em permanente evolução, mas que não possui uma história própria independente das prestações estéticas que ela mesma atualiza. Assim, cada obra produzida é concebida com o conhecimento dessas regras, quer elas sejam admitidas de maneira implícita, quer sejam explicitadas ou mesmo transgredidas (POINSOT, 1999, p. 35, tradução nossa).

Muitos aspectos considerados eminentemente técnicos, relativos, por exemplo, ao trabalho de montagem, à opção por determinado tipo de iluminação, ou a exigência do uso de etiquetas de identificação e sua localização próxima ou distante da obra, enquadram-se entre o que Poinsot (1999, p. 30, tradução nossa) apresenta como "pressupostos e subentendidos" do enunciado expositivo, parte integrante e significativa para a construção de seus sentidos e significados.

As práticas de exposição possuem sua própria história e nos últimos anos temos observado um interesse crescente pelo estudo, pesquisa e debate sobre este segmento da produção cultural. A problematização das relações entre os objetos artísticos e o lugar de exposição, postos em cena pelas obras que se configuram como instalações, site-specific e in situ contribuiu de forma significativa para um questionamento da ideologia implícita na proposição de um espaço expositivo neutro ou neutralizável, conforme os termos postos pela noção de cubo branco. A disseminação das grandes exposições internacionais de arte contemporânea, especialmente o formato "bienal", fez-se acompanhar do protagonismo conferido à figura do curador, como autor e artífice da exposição, deslocando o crítico - no caso, aquele profissional cuja produção se realiza eminentemente através da produção textual, veiculada de modo sistemático através de alguma mídia - para um segundo plano.

$O$ aquecimento do mercado de arte, evidenciado não somente pelo crescimento no número de galerias de arte, mas também pela proliferação das feiras internacionais de arte contemporânea, também provocou a busca de maior compreensão sobre a lógica que preside as relações, nem sempre transparentes, que configuram as redes de interesses entre instituições museológicas, academia, crítica, colecionismo corporativo e privado ou a precificação de obras de arte contemporânea e que podem culminar em uma grande exposição de arte internacional. Um cenário assim diversificado, aliado ao desenvolvimento tecnológico, provavelmente colaborou para o desenvolvimento da profissionalização no campo do design de exposições, atividade que ganha cada vez mais espaço junto ao trabalho de curadoria ${ }^{3}$. Em um contexto assim delineado, tornou-se necessário operar com os aspectos técnicos e simbólicos da exposição não mais como um "dualismo", isto é, como "dois conjuntos de fenômenos dados independentes" e, sim, como dimensões que se organizam recursivamente, ou seja, como dualidade no sentido proposto por Giddens (2009, p. 30).

De modo geral, a proposição de uma exposição de artes visuais - neste momento, não importando as dimensões materiais ou institucionais deste evento,

\footnotetext{
3 Nos limites do presente texto, opero com uma concepção de museografia como um conjunto de conhecimentos e práticas mais diretamente relacionados ao campo museológico e que extrapola, englobando, as práticas e competências específicas relacionadas aos diversos procedimentos exigidos pela montagem de uma exposição. Para designar o trabalho específico relacionado aos projetos que viabilizam a montagem da exposição, incluindo a distribuição das obras no recinto da galeria e os demais recursos técnicos necessários, tais como mobiliário de apoio, iluminação, programação visual etc., optou-se por empregar em alguns casos o termo "expografia” e, em outros, “design de exposição”, em caráter de certo modo intercambiável, ainda que assinalemos as sutilezas semânticas que especificam a adoção de um e outro.
} 
desde uma pequena mostra individual, a uma coletiva de acervo ou uma bienal internacional -, incluindo o trabalho de curadoria, a expografia e a produção do catálogo, tanto no que concerne ao teor dos textos, quanto ao design gráfico-editorial, segue a máxima vigente no campo das artes, isto é, a ênfase na autoria, em um movimento que vai do autor, seja ele o artista ou o curador, para o público.

Observo que "autoria" é entendida aqui como a possibilidade de expressar uma visão de mundo, podendo se apresentar como autoria individual, coletiva ou produção colaborativa. Tenho em conta, ao propor esta definição ampla, que a "autoria" torna-se uma questão problemática no campo artístico contemporâneo e que sua discussão vai além dos limites impostos pelo regime autográfico. Seja como for, um trabalho de arte comporta em algum nível a ideia de autoria, mesmo que de um ponto de vista crítico.A ideologia artística está assentada na pretensão de que o trabalho do artista - isto é, do autor, em sentido amplo - possua elevado valor simbólico. Em termos convencionais, ao público é oferecida a possibilidade de vivenciar ou compartilhar tal experiência, mas não enquanto protagonista da ação artística. Dito de outro modo, o foco está na arte e na produção e, em um grau secundário, na distribuição ou na comunicação. A qualificação de uma exposição de arte como "didática" será considerada uma ofensa grave por parte de seus autores, sejam curadores, artistas, museógrafos ou designers. Em suma, o consumo intelectual da arte exige certo grau de competência e disposição, tanto dos profissionais atuantes no campo, quanto do público, como forma de distinção entre os produtos gerados por uma cultura superior em relação à fruição dos produtos gerados pela indústria do entretenimento.

Também como regra dominante - encontraremos exceções, se procurarmos com cuidado - assim como as obras, também as curadorias e expografias das mostras de arte contemporânea têm seus interlocutores ideais, localizados entre o segmento especializado do público e entre os próprios pares. Por outro lado, no cenário atualmente configurado pela introdução do pensamento e das práticas neoliberais operando como princípios norteadores das políticas de gestão e financiamento no campo da cultura, atender às demandas do visitante-cliente tornou-se um fator chave para alcançar um saldo positivo na relação custo-benefício. Como observam os especialistas no tema, uma exposição com alto orçamento, viabilizada através de investimentos privados associados ao marketing, deverá responder com números expressivos em termos de público. Neste contexto, a opção pela lógica do entretenimento, pela sedução através do oferecimento de um "produto-satisfação" - isto é, uma exposição convencional, que apenas reforçaria os parâmetros de gosto já cristalizados, porém com uma roupagem visual ou um discurso pretensamente contemporâneo segundo os parâmetros da indústria cultural - pode ser a opção mais fácil e o caminho mais rápido para um tipo de sucesso que, a rigor, representaria "o enfraquecimento da dimensão política do museu” (MENESES, 1994, p. 24). Seguindo esta linha, Cury (2005) argumenta que o "respeito ao público", por parte dos gerenciadores e programadores de eventos atuantes nas instituições museológicas deveria residir exatamente na proposição de "produtos-inquietação resultado da interação do visitante com a exposição" e não de meros "produtos-satisfação" (CURY, 2005, p. 67) destinados a funcionar como simples entretenimento segundo uma lógica do espetáculo. 
O conjunto de ações que envolvem a atividade de visitar uma exposição inscreve-se na ampla gama de rotinas institucionalizadas que configuram nossa vida social - para empregar as noções de Giddens (2009) - isto é, tal atividade comporta uma sequência de atitudes corporais e intelectuais específicas. Embora utilizemos de forma recorrente e coloquial a expressão "ver uma exposição" para designar tal situação, é certo que para efetivar esta atividade empregamos nosso corpo no fluxo da ação, agenciando a totalidade de nossos sentidos em uma experiência do movimento corporal durante a qual "fazemos acontecer" a ação - consciente deliberada - de vivenciar uma exposição. Um aspecto aparentemente banal da ação de visitar uma exposição consiste no fato de que tal vivência ocupa uma duração de tempo no fluxo da vida, mas diferentemente de outras manifestações artísticas nas quais 0 tempo é pré-definido pela linguagem específica da obra - por exemplo, uma peça de teatro, um concerto, um filme -, a duração pode ser estabelecida pelo visitante-espectador. É possível que um determinado visitante, em dada circunstância, efetive uma permanência muito breve no interior de uma mostra de razoáveis proporções e grande número de obras ou, pelo contrário, permaneça durante um longo período de tempo em outra mostra bastante pequena no que concerne à quantidade de obras, às dimensões do recinto destinado a sua montagem ou à complexidade do circuito proposto para a visitação pela curadoria.

Nestes termos, uma mostra que apresente um conjunto expressivo de trabalhos em videoarte - um gênero das artes visuais que possui uma duração específica e que exige um tempo determinado para sua apreciação -, impõe um uso do tempo disponível por parte do visitante que é potencialmente distinto da situação configurada por uma mostra que apresente objetos ou imagens fixas, tais como pinturas, fotografias, esculturas ou mesmo instalações. Por fim, a própria determinação do que seja um período curto ou um período longo de tempo, no que concerne a contagem dos minutos ou horas ocupados para visitar e vivenciar uma exposição, é algo que se torna objeto de discussão e que é, em alta dose, uma delimitação de ordem subjetiva. Não existe uma regra que especifique o tempo adequado para a apreciação de uma obra de artes visuais, assim como um poema de poucos versos pode incentivar mais tempo de fruição do que um romance com várias páginas. Mas não é a este tipo de experiência temporal destinado às condutas estéticas que me reporto no momento e, sim, aos aspectos mais factuais do uso do tempo cronológico para realizar uma visita a uma exposição, considerando que não se trata de uma conduta social com tempo de duração demarcado de antemão.

Ao visitar uma exposição, não precisamos dedicar o mesmo grau de atenção a todas as obras dispostas no recinto da galeria ou aos outros componentes de ordem museográfica que a constituem. Estes últimos, especialmente as chamadas ferramentas expográficas, são considerados na maioria dos casos e pela maior parte dos visitantes, como "pressupostos". É o caso, por exemplo, da presença de etiquetas e de sua localização junto a cada obra, das paredes brancas ou mesmo do tipo de iluminação que pode ser empregada tanto como um foco sobre determinado objeto, destacando-o do conjunto e conferindo um certo componente de dramaticidade ou como um "banho de luz”, que, por seu turno, tenderá a uniformizar a percepção das peças 
expostas no recinto. Do ponto de vista de um visitante leigo, a altura das vitrines raramente é percebida como um recurso que condiciona a visualização adequada de seu conteúdo a uma determinada estatura da parte do visitante. Tampouco o tipo ou o tamanho da fonte empregado nos textos adesivados nas paredes será considerado como um componente indutor ou dificultador para o processo de leitura. No entanto, do ponto de vista do museógrafo ou do designer de exposição, tais opções, consideradas de ordem técnica, são tomadas de forma intencional. Mais precisamente, o conhecimento que estes especialistas dispõem é empregado deliberadamente para produzir determinado efeito. No caso, um efeito de ordem simbólica.

Conceber, planejar e montar uma exposição demanda um trabalho em equipe, para o qual concorrem profissionais com formações e experiências variadas, e cuja realização exigirá proceder a uma série de negociações tendo em vista o resultado final almejado. Do ponto de vista do artista, sua obra é o foco principal e a razão de ser de uma exposição. Segundo este enfoque, as condições de existência da obra - em termos materiais, conceituais, estéticos - e seus modos específicos de espacialização devem ser assumidos como prioridade pela curadoria, materializando-se no design da montagem e sendo registrada, "da maneira adequada" (segundo os parâmetros do artista-autor da obra) pela edição de imagens no catálogo da exposição. Do ponto de vista do curador, por sua vez, o propósito consiste em ressaltar as conexões entre as obras escolhidas, para além da mera soma de individualidades. Enquanto isto, o discurso museológico aponta a "experiência do público" como a chave de ignição para a concepção e montagem de uma exposição.

Estes pontos de vista não são excludentes, nem contraditórios, mas equacioná-los de uma forma satisfatória pode significar um embate intenso entre posições nem sempre convergentes em um ambiente de acirrados jogos de poder. Por certo, temos em conta que a própria definição do que venha a ser, em termos concretos, uma "equação satisfatória" entre as proposições dos diferentes agentes que se consideram como autores da exposição - isto é, o artista, o curador, o designer de exposição, o museólogo, o patrocinador, o marchand etc. -, deve ser objeto de discussão e reflexão. Nesta situação (como em muitas outras), o pensamento de Boudieu segue profundamente elucidativo:

O produtor do valor da obra de arte não é o artista, mas o campo de produção enquanto universo de crença que produz o valor da obra de arte como fetiche ao produzir a crença no poder criador do artista. Sendo dado que a obra só existe enquanto objeto simbólico dotado de valor se é conhecida e reconhecida, ou seja, socialmente instituída como obra de arte por espectadores dotados da disposição e da competência estéticas necessárias para conhecer e reconhecer como tal, a ciência das obras tem por objeto não apenas a produção material da obra, mas também a produção do valor da obra ou, o que dá no mesmo, da crença no valor da obra (BOURDIEU, 1996, p. 259, grifo do autor).

A exposição e a rede institucional e de agentes que a produz, promove e sustenta é parte constitutiva deste processo de construção da crença no valor da obra. E, de modo concreto, as opções por uma determinada localização, pela vizinhança ou pelo distanciamento entre duas ou mais obras de um mesmo artista ou de artistas de diferentes gerações e posicionamentos 
conceituais e estéticos, chegando à escolha por uma iluminação mais dramática ou pretensamente neutra, são decisões aparentemente técnicas que participam deste discurso e desta construção de valor, sejam ou não percebidas como implícitas, explícitas ou pressupostas.

Porém, se o "produtor do valor da obra de arte não é o artista" isolado, - mesmo deve ser aplicado à figura do curador, no que concerne à produção do valor da exposição. Para além dos produtores diretos da obra e da exposição em sua materialidade (o artista, o curador, o designer de exposição, o museólogo etc.), como lembra Bourdieu (1996, p. 259), é necessário levar em conta o conjunto de agentes e instituições artísticas que atuam no processo de formação profissional, reconhecimento e consagração, as instâncias políticas e administrativas que regulam as políticas culturais para o setor, o mercado de arte em seus diversos desdobramentos e, no cenário atual, o papel desempenhado pela mídia, também em seus diferenciados veículos.

De uma forma esquemática, uma exposição consiste em um conjunto de obras, resultado de um processo de seleção a partir de determinados critérios estabelecidos pelo artista, pelo curador e/ou pela instituição, unificado por um título e disponibilizada ao público-visitante segundo uma disposição específica em um dado lugar (por sua vez, caracterizado por determinados atributos arquitetônicos e geográficos), por um período de tempo. Embora as relações entre estes diversos fatores - especialmente a distribuição das obras no local de exposição - possa ser simulada antecipadamente através de programas de design gráfico, cada vez mais sofisticados em termos tecnológicos, é somente no efetivo exercício da montagem em espaço real que a exposição toma corpo e a experiência estética, artística, vivencial torna-se possível, inclusive para seus autores, sejam os artistas, os curadores ou os museógrafos. A exposição somente se efetiva com a experiência observacional em contato direto, no espaço de exibição, em um determinado recorte temporal, como decorrência das especificidades determinadas pelos modos de espacialização adotados pelos artistas em suas obras individuais e pelos curadores e designers de exposição, no que concerne ao conjunto. Dito de forma direta: o momento da montagem é crucial e decisivo.

Este evento de caráter temporário, destinado a ser vivenciado em termos fenomenológicos, será, por sua vez, editado em um catálogo ou livro de exposição. O catálogo exerce diversas funções, entre elas a de divulgação - do evento em si mesmo, assim como da instituição promotora ou da marca do patrocinador, seja público ou privado - e também a de registro e documentação, do ponto de vista da história e da crítica de arte. Um catálogo também é uma peça de design gráfico e participa da história específica desta disciplina, através das opções técnicas de impressão, do uso de uma determinada fonte gráfica, tipo de papel, variedade de cores, entre outros aspectos.

Escolhas de ordem técnica e estética no design gráfico dos catálogos repercutem significativamente no grau de legibilidade dos textos, das informações sobre as obras e, evidentemente, na memória sobre a exposição. Considere-se, por exemplo, o hábito de incluir somente imagens isoladas das obras presentes na exposição, as quais, embora estejam acompanhadas de legendas que informam sobre suas dimensões específicas, são representadas através de fotografias equalizadas em tamanho na página do catálogo, eliminando as diferenças de escala. $O$ desenvolvimento e a popularização das 
técnicas de editoração e impressão, aliados ao protagonismo das instalações e outras obras que se configuram a partir de uma disposição específica no recinto de exposição, desempenharam um papel relevante na inclusão de imagens de vistas gerais do recinto de exposição, permitindo uma documentação mais adequada das relações entre as obras, o espaço da galeria e as opções de ordem curatorial e expográficas. Nos últimos anos, inclusive, muitos catálogos impressos se fazem acompanhar de mídias DVD ou links para sítios na internet, a partir dos quais podemos acessar uma visita virtual pelo circuito proposto para a exposição, para além dos limites impostos por seu período de visitação.

Isto posto, o catálogo se constitui, a rigor, como uma outra linguagem e modalidade de interpretação da exposição, na medida em que apresentará o texto do curador (geralmente com a argumentação sobre suas intenções norteadoras e os critérios adotados para a seleção de obras e artistas) acrescido das imagens das obras e/ou da exposição montada. As opções adotadas na edição de textos, imagens e no design gráfico do catálogo não devem ser reduzidas ao estatuto de mero registro da exposição. Descrever envolve selecionar e definir, e estes procedimentos, como sabemos, constituem um trabalho de interpretação.

Seguindo esta linha de raciocínio, partilho da categorização apresentada por Weschler, quando a autora articula a produção curatorial a uma ação política:

Trata-se de pensar a produção curatorial e a produção de textos críticos como ações políticas (entendidas como estratégias de posicionamento dentro do espaço da produção de saberes), dado que são gestos responsáveis pela delimitação de um corpus e um olhar preciso sobre certos aspectos do mundo contemporâneo; constroem representações socioculturais de índole distinta, intervindo na formação de diversas noções identitárias de gênero, nação, região, classe, etc. (segundo os casos), que vão se instalando no imaginário de nossas sociedades. (WESCHLER, 2010, p. 70, grifo do autor)

Neste ponto, retomo as noções propostas por Giddens, (2009) incorporando as distinções que o autor estabelece entre "intenção" e "motivo" e, especialmente, suas considerações sobre as "consequências não premeditadas da ação" ${ }^{4}$. Para Giddens (2009), convém ressaltar, a ação "não é uma mera combinação de 'atos", e, sim, um complexo "conjunto de processos incrustados" que envolve "a monitoração reflexiva" por parte do agente, isto é, do perpetrador da ação, “a racionalização e a motivação da ação” (GIDDENS, 2009 , p. 4), concepção que parece pertinente quando aplicada em uma reflexão sobre a sutil articulação entre processos cognitivos, intuitivos e prático/ experimentais, que caracterizam a ação de curar e montar uma exposição. Do mesmo modo que não se resume a um ato, "a ação intencional não se compõe de um agregado ou série de intenções, razões e motivos isolados”. $O$ autor prossegue, observando que:

4 Em seu livro “A Constituição da Sociedade”, originalmente publicado em 1984, Giddens (2009) tem objetivos bastante ambiciosos e amplos ao teorizar sobre a ação, a agência, o agente e os desdobramentos conceituais e operacionais de cada uma destas categorias e suas aplicações ao estudo das rotinas da vida social. Não alimento a ilusão de resumir a complexa rede de articulações teóricas e de exemplos oferecidos pelo autor. Pretendo, isto sim, utilizar seu raciocínio para alimentar uma reflexão que considero pertinente e pouco explorada nos debates que atualmente discutem o "poder" ou a função do curador ou de qualquer outro agente isolado. 
Assim, é útil falar da reflexividade como algo assentado na monitoração contínua da ação que os seres humanos exibem, esperando o mesmo dos outros. A monitoração reflexiva da ação depende da racionalização, entendida aqui mais como um processo do que como um estado, e como inerentemente envolvida na competência dos agentes (GIDDENS, 2009, p. 3-4).

Evidentemente, Giddens não ignora que a capacidade tipicamente humana para "elaborar discursivamente" e comunicar as possíveis razões, motivos e intenções para uma determinada ação também inclui mentir sobre elas, assim como o fato de que nem todo o conhecimento é, ou está sempre, acessível à consciência dos atores (GIDDENS, 2009, p. 5).

Tendo em conta que a ação de curar e montar uma exposição pode ser definida como uma "conduta motivada" de forma consciente (o que não deve nos levar a confundir com a presunção de que todas as motivações envolvidas nesta ação sejam totalmente transparentes para os seus respectivos perpetradores, pois sempre existirão "zonas obscuras"), o "principal critério de competência" que os agentes esperam dos outros é o de que "os atores", neste caso, por exemplo, o curador, o artista, o responsável pelo design da exposição, "sejam [...] capazes de explicar a maior parte do que fazem, se indagados" (GIDDENS, 2009, p. 6).

Cumpre observar, ainda, que Giddens (2009) estabelece uma diferença entre "motivo" e "intenção", entendendo que o primeiro refere-se mais ao "potencial para a ação", as "necessidades", conscientes ou não plenamente conscientes, que instigam à ação e não exatamente ao modo específico como uma dada ação é executada, este último sim, relativo ao campo da intencionalidade.

Embora atores competentes possam quase sempre informar discursivamente sobre suas intenções ao - e razões para - atuar do modo como atuam, podem não fazer necessariamente o mesmo no tocante a seus motivos. A motivação inconsciente é uma característica significativa da conduta humana [...] (GIDDENS, 2009, p. 7).

Esta observação é tanto aplicável às situações mais corriqueiras da vida cotidiana, quanto ao trabalho do artista ou do curador. Neste âmbito coloca-se a distinção entre "o que pode ser dito", e que Giddens (2009, p. I7) define como "consciência discursiva" e o que pode efetivamente ser feito em determinadas circunstâncias, definido pelo autor como "consciência prática". Seja como for, especialmente no caso de ações mais complexas - nas quais se enquadram as variadas condutas envolvidas na concepção, curadoria e montagem de uma exposição - não é possível aos agentes envolvidos, apesar de todo planejamento prévio e competência manifesta, controlar as consequências e repercussões de forma integral. Não se trata de uma falha, trata-se de uma propriedade das ações, especialmente as de caráter complexo.

Por certo, o grau de poder - se é possível falar nestes termos - de uma instituição ou de uma exposição para modelar as concepções vigentes sobre arte - sobre o que deve ser reconhecido e consagrado como arte de qualidade, como arte plenamente válida - em determinado contexto, dependem de seu potencial de difusão por um lado - vivemos em uma sociedade midiática - e de sua "capacidade para "criar uma diferença", isto é, para "influenciar" os poderes, os comportamentos, as concepções "manifestados pelos outros", 
afetando o modo como o próprio circuito processa sua rede e encontra força em determinados pontos (agentes, instituições, mercado) através de suas conexões. Quanto maior a amplitude do raio de interferência manifestado por um agente ou instituição, maior seu grau de poder. Decorre daí que as - consideradas por muitos como antigas e ultrapassadas - noções de centros hegemônicos e de periferia, permanecem válidas, ainda que os seus limites, fronteiras e linhas de força se manifestem de forma mais permeável nos dias atuais do que em décadas passadas. Vivenciamos um período em que o território da arte se amplia e suas coordenadas se entrecruzam, tanto no que concerne aos lugares de proveniência dos artistas ou curadores que atuam nas grandes exposições contemporâneas, quanto na geografia dos próprios eventos. Seria ingenuidade, porém, imaginar que tais processos em escala internacional funcionam de forma efetivamente inclusiva, compartilhada e não hierarquizada 5 .

Seja como for, na medida em que um museu ou instituição cultural estabelece critérios - mais ou menos claros, mais ou menos obscuros -, para a formação de seu acervo, para estabelecer suas prioridades em política cultural, para a eleição daqueles que irão compor seus conselhos curatoriais ou consultivos, para buscar parcerias que viabilizem financeiramente os projetos do museu/centro cultural/fundação, para convidar curadores e, estes, para selecionar obras ou artistas para exposições, estarão sendo definidas as molduras e os enquadramentos para o que será apresentado como arte por parte desta mesma instituição. Em outras palavras, se o alcance e o poder de difusão, manifestados por uma instituição museológica em um circuito hegemônico funcionam como enquadramento e moldura, a escassez ou o silêncio também operam na instauração de um lugar para a arte em determinado contexto, ainda que através de uma agenda negativa.

Neste ponto da reflexão, penso ser considero mais produtivo considerar a exposição como dispositivo e menos como resultado da agência individualizada de um agente específico, neste caso, o curador. Com isto não estou negando o papel desempenhado pelo curador no cenário atual, suas injunções nos jogos de poder engendrados entre campo da arte e o social, nem o caráter midiático que tal personagem pode assumir. Se voltarmos a concepção de poder expressa por Giddens (2009) como a "capacidade de obter resultados", pode ser esclarecedor pensar quais os limites e qual a liberdade de ação de cada um dos agentes envolvidos em um projeto de exposição, desde o diretor do museu, passando pelos patrocinadores, pelo curador, pelos artistas, designers de exposição, entre outros profissionais responsáveis pela efetivação do evento.

Diversos autores, segundo diferentes enfoques têm relacionado a noção de dispositivo ao campo da arte contemporânea, especialmente no âmbito das pesquisas em artemídia e no segmento que articula arte e tecnologia digital. Para além de sua plasticidade, tenho em conta que o termo está sujeito a variações em sua definição, segundo diferentes autores ou contextos de aplicação e também que uma revisão mais detalhada de sua genealogia ou

5 É importante sinalizar que a definição de poder em Giddens (2009) difere da operada por Foucault, como o próprio cientista social inglês ressalta. Embora Giddens (2009, p. 302) não descarte os componentes coercitivos ou a existência de conflito, o mote central no qual apoia sua noção de poder é a "capacidade de obter resultados" e os recursos que podem ou não ser empregados por um determinado agente em dada situação para atingir os objetivos propostos. 
mesmo de suas delimitações por parte dos autores referenciais - Foucault e Deleuze, por exemplo - extrapolaria os limites propostos para este artigo.

Feita esta ressalva, considero que, além da riqueza semântica do termo, ou de seu potencial metafórico, a noção de dispositivo aplicada ao campo das exposições permite ir além da dicotomia técnico-simbólica que permeia parte significativa dos estudos sobre o tema, assim como relativiza a tendência a depositar excessiva ênfase na observação de um único componente do conjunto, seja ele o curador, o artista, a obra, a expografia ou a instituição, entre outros desdobramentos possíveis. Dito de outra forma, considerar a exposição a partir de uma concepção de dispositivo representa uma tentativa de compreendê-la enquanto fenômeno complexo, como "um conjunto multilinear", cujas linhas estabelecem trajetórias em múltiplas direções, tanto se aproximam, quanto se afastam, configurando um circuito em rede (DELEUZE, 1989, p. I85).

Para além do olhar que tende a separar os aspectos mais "técnicos" como poderiam ser enquadrados aqueles relativos à montagem ou mesmo determinadas opções de ordem expográfica - de outros assumidos como mais "autorais" ou "artísticos", tais como a curadoria ou obras de caráter in situ e site specific, falar da exposição como dispositivo "permite fazer coexistir, no centro da argumentação, entidades tradicionalmente consideradas como inconciliáveis" (PETERS; CHARLIER, 1999, p. 16). Segundo um ponto de vista interacionista, a exposição como dispositivo deve ser considerada tanto no que concerne aos aspectos de produção, quanto de recepção. Ou melhor, um momento e outro, o da produção e o da recepção, enquanto linhas constitutivas de uma rede, representam a passagem para um entendimento da exposição como "experiência ou como experimentação" de um saber (PETERS; CHARLIER, 1999, p. I8), seja do ponto de vista do curador, do museógrafo, do público ou, mesmo, da instituição.

Outro ponto a ressaltar, é apresentado por Agamben em sua leitura da concepção de dispositivo em Foucault. Para o filósofo italiano "o dispositivo tem sempre uma função estratégica concreta e se inscreve sempre em uma relação de poder" (AGAMBEN, 2009, p. 10) ${ }^{6}$. Mais uma vez, tal percepção pode ser considerada pertinente - tendo em vista as especificidades de cada posição - tanto no que concerne às opções de ordem mais aparentemente técnicas, como à opção pelo teor dos textos presentes no recinto de exposição, sua extensão, localização e mesmo o tamanho das fontes em que será impresso, às determinações institucionais para a escolha e convite a um determinado curador, aos limites de verba para financiamento das ações e das equipes do setor educativo ou às opções do público por um determinado circuito no recinto de exposição. Não ignoro a máxima metodológica de que uma categoria suficientemente abrangente para abarcar tudo muito provavelmente não possa explicar, efetivamente, nada. Para além deste possível prejuízo, volto a enfatizar o aspecto produtivo percebido na concepção de exposição como dispositivo, qual seja o de compreendê-la como um todo, resultado do cruzamento de linhas de força - as quais, como em todo dispositivo, não são necessariamente evidentes ou igualmente evidenciadas - entre diversos agentes, agenciamentos, instituições e público, postos em tensão/ação.

6 Agamben opera a noção de poder mais próximo aos termos de Foucault, ressaltando os aspectos de dominação e conflito. 


\section{Referências}

AGAMBEN, Giorgio. O que é um dispositivo? Tradução Nilcéia Valdati. Outra Travessia, n. 5, p. 9-16, 2005.

BLANCO, Ángela García. La exposioción: un medio de comunicación. Madrid: Akal, 1999.

BOURDIEU, Pierre. As regras da arte: gênese e estrutura do campo literário. Tradução Maria Lucia Machado. São Paulo: Companhia das Letras, 1996.

CURY, Marilia Xavier. Exposição, montagem e avaliação. São Paulo:Annablume, 2005. DELEUZE, Gilles. Qu'est-ce qu'un dispositive? In: MICHEL Foucault Philosophe. Paris: Seuil, 1989. (Annales rencontre internationale).

GIDDENS, Anthony. A constituição da sociedade. Tradução Álvaro Cabral. 3. ed. São Paulo: Martins Fontes, 2009.

GUASCH,Anna Maria. Los manifiestos del arte posmoderno. Madrid:Akal, 2000.

MENESES, Ulpiano Bezerra. Do teatro da memória ao laboratório da história: a exposição museológica e o conhecimento histórico. Anais do Museu Paulista, v. 2, p. 9-42, 1994.

PEETERS, Hugues; CHARLIER, Philippe. Contribuitions à une théorie du dispositif. Hermés. Le Dispositif: entre usage et concept, n. 25, p. I5-23, 1999.

POINSOT, Jean-Marc. Quand l' oeuvre a lieu: l' art exposé et ses récits autorisés. Genève: Mamco, 1999.

WESCHLER, Diana Beatriz. Relatos curatoriais, relatos políticos. In: JAREMTCHUCK, D.; RUFINONI, P.Arte e política: situações. São Paulo:Alameda, 2010. 